\title{
Audit
}

\section{Thyroid dysfunction in adults with Down's syndrome}

\author{
Tharayil Suresh, Staff Grade Psychiatrist; and Pauline Robertson, Consultant \\ Psychiatrist, Royal Scottish National Hospital, Larbert, Stirlingshire FK5 6EH
}

Thyroid treatment was used at the beginning of the 20 th century for people with Down's syndrome, and an improvement in the physical and mental response was noted (Smith \& Berg, 1976). Later studies reported conflicting findings about the prevalence and type of thyroid dysfunction (Sare et al, 1978; Lobo et al, 1980) but there now seems little doubt about the existence of a high prevalence of hypothyroidism (Mani, 1988; Dinani \& Carpenter, 1990).

Clinical detection of early cases of hypothyroidism in Down's syndrome can be difficult, as the two conditions have many features in common. In order to prevent people with Down's syndrome having an additional handicap due to a treatable condition, it is important to ensure regular biochemical screening.

An audit was carried out on the thyroid status of 69 in-patients with Down's syndrome at the Royal Scottish National Hospital and a computerised system established to facilitate recall for future testing.

\section{The audit process}

At a meeting of the hospital's Medical Audit Committee, it was agreed that the therapeutic aim was to achieve euthyroid status in all individuals with Down's syndrome. This would be assessed from their biochemical thyroid function tests, using TSH and thyroxine levels.

The frequency of testing was discussed, and some fairly arbitrary standards were set-every subject should be offered the test at least every three years; those already on thyroxine should be tested annually and those who were being stabilised on treatment should have more frequent tests, the minimum being every six months. The co-operation of the local biochemistry laboratory was obtained.

The first step of the audit cycle consisted of establishing the existing thyroid status of Down's patients, the second of adjusting their medication if necessary, and the third of repeating the thyroid function tests within the specified time limits and identifying any new or inadequately treated cases of thyroid disorder. The time limits could be adjusted if necessary, e.g. if it were found that several new cases of hypo- thyroidism occurred within the three year review period.

The first and second steps have been completed, and a system established to enable the further tests to be carried out.

\section{Subjects}

The hospital had 69 residents with Down's syndrome confirmed by chromosomal analysis, out of a total of 582 in-patients. Forty-four were male and 25 female. The age range was 22-69 years, with a mean of 43 years.

\section{Step 1 - Existing thyroid status}

Forty-six subjects (33 male and 13 female) had thyroid function tests within normal limits. Eleven known and three new cases of hypothyroidism, with a raised TSH and low thyroxine level, were identified. Seven cases has raised TSH but normal thyroxine levels, coming into the category of sub-clinical hypothyroidism. There was one known case of hyperthyroidism and one new case of sub-clinical hyperthyroidism (normal TSH, raised thyroxine).

\section{Step 2 - Adjustment of medication}

Eleven subjects were already receiving thyroxine supplements. The dosage had to be adjusted in two cases (one increase, one decrease). One subject was on carbimazole at a satisfactory dose. Thyroxine therapy was instituted in three cases.

\section{Establishment of a recall system}

The names, date of birth, ward, date of last thyroid check and date of next check were entered into a database to facilitate recall. Every month, patients who are due to be screened are identified and arrangements made with the ward doctor for the blood tests to be carried out and the results returned to the doctor responsible for the thyroid project.

The results will be reviewed annually by the Audit Committee, and the audit cycle completed by revising the standards if necessary until the most 
appropriate interval for checking the thyroid function is determined.

\section{Comment}

This project confirmed the existence of a high prevalence of thyroid disorders among people with Down's syndrome. Fourteen out of the 69 subjects $(20 \%)$ had hypothyroidism, and a further seven $(10 \%)$ had subclinical hypothyroidism, while there was one definite and one sub-clinical hyperthyroidism. A sex difference was noted, with 12 of the 25 females ( $48 \%$ ) and 9 of the 44 males $(20 \%)$ having clinical or sub-clinical hypothyroidism, while the two cases of hyperthyroidism were male. Thyroid disorder was sufficiently commonly found to make a regular review both of the thyroid function tests and medication worthwhile. Although this system was devised for use with a group of in-patients, it could be adapted for use with people with Down's syndrome living in the community.

\section{References}

DinANI, S. \& CARPENTER, S. (1990) Down's syndrome and thyroid disorder. Journal of Mental Deficiency Research. 34, 187-193.

LoBo, E. DE H., Khan, M. \& TEw, J. (1980) Community study of hypothyroidism in Down's syndrome. British Medical Journal, $i, 1253$.

Mani, C. (1988) Hypothyroidism in Down's syndrome. British Journal of Psychiatry, 153, 102-104.

Sare, Z., Ruvalcaba, R. H. A. \& Kelley, V. C. (1978) Prevalence of thyroid disorder in Down's syndrome. Clinical Genetics, 14, 154-158.

SMith, G. F. \& Berg, J. M. (1976) Down's Anomaly. London: Churchill Livingstone.

\title{
Who is watching them? A study of the interpretation of the observation policy in a mental health unit
}

\author{
Christine M. Hodgson, Registrar; JoAnne Kennedy, Registrar; Paloma Ruiz, Senior \\ House Officer; Michael LANGENBACH, Registrar; STEVE MOORHEAD, Registrar, \\ Mid-Trent Psychiatric Rotational Training Scheme; and Ola JuNAID, Senior \\ Registrar, Mapperley Hospital, Nottingham NG3 6AA
}

\section{The study}

Observation levels are widely used in the management of acutely disturbed psychiatric patients (Shugar \& Rehaluk, 1990). Although clinicians are involved in decisions about observation levels, there is rarely any specific training and very little formal structure to the decision making process. We report a survey of the views and knowledge of clinical staff regarding observation levels. Questionnaires were sent to all the nurses of the six acute psychiatric wards in the Nottingham Mental Health Unit, and all the doctors involved in the care of patients on these wards.

\section{Findings}

The response rate to the questionnaire was $65 \%$ overall, with $46(60 \%)$ of the 77 doctors responding and $53(71 \%)$ of the 75 nurses responding. Of the doctors, $26 \%$ were consultants, $22 \%$ senior registrars, $22 \%$ registrars and $30 \%$ senior house officers. Over half of the nurses were staff and enrolled nurses $(57 \%)$. Ward managers and deputy ward managers each comprised $13 \%$, and untrained staff $17 \%$.

\section{Stafi views on observation levels}

Respondents were asked to rank five factors in order of how important they were in assessing a patient's level of risk of harm to self or others, scoring 5 for most important and 1 for least important: $A$ - mental state examination; B - past history of the patient; C patient's current behaviour; $D$-patient's expressed intentions; $\mathrm{E}$-intent implied from the patient's behaviour. For each grade, the median score allocated to each of the five choices was calculated. There was wide variation in replies among doctors (Kendall's coefficient of concordance of 0.22 ). However, the 